\title{
As teorias do mínimo existencial e da reserva do possível como retrocessos à efetivação do direito à saúde no Brasil
}

Minimum existential and possible reservation theories as setbacks to the implementation of the right to health in Brazil

\section{Jarbas Ricardo Almeida Cunha ${ }^{1}$}

Resumo: Este artigo analisa as teorias do mínimo existencial e da reserva do possível como retrocessos à efetivação do direito à saúde no Brasil. Utiliza-se a metodologia histórico-dialética para demonstrar o caminho da construção intelectual de ambas as teorias, desde o surgimento no direito constitucional alemão até sua aplicação no constitucionalismo brasileiro com os específicos impactos no Direito Sanitário em nossa realidade.

Palavras-chave: Mínimo Existencial, Reserva do Possível, Direito à Saúde.

Abstract: This article examines the theories of minimum existential and possible reservation as setbacks to the implementation of the right to health in Brazil. It uses the historical-dialectic methodology to demonstrate the path of intellectual construction of both theories, since the appearance in German constitutional law until its implementation in the Brazilian constitutionalism with specific impacts on Health Law in our reality.

Keywords: Minimum existential, Possible reservation, Right to Health.

Resumen: Este artículo examina las teorías del mínimo existencial y reserva del posible como retrocesos en la realización del derecho a la salud en Brasil. Utiliza la metodología histórico y dialéctica de demostrar el camino de la construcción intelectual de ambas teorías, desde su orígen en el derecho constitucional alemán hasta su aplicación en el constitucionalismo brasileño con los impactos específicos sobre el Derecho a la Salud en nuestra realidad.

Palabras-Ilave: Mínimo Existencial, Reserva del Posible, Derecho a la Salud.

\section{Introdução}

Abordaremos neste artigo o percurso intelectual das teorias do mínimo existencial e da reserva do possível, desde seu advento no direito constitucional alemão, por meio da interpretação da Lei Fundamental de Bonn, até sua aplicação no direito constitucional brasileiro e seus reflexos na aplicação do direito à saúde no Brasil.

\footnotetext{
${ }^{1}$ Graduado em Direito pela Universidade Federal de Ouro Preto - UFOP. Especialização em Direito Sanitário pela Fundação Oswaldo Cruz - Fiocruz Brasília. Mestrado em Política Social pela Universidade de Brasília - UnB. Analista Técnico de Políticas Sociais (ATPS) no Ministério do Desenvolvimento Social e Combate à Fome (MDS). Professor de Direito Constitucional Sanitário. E-mail: jarbas.ricardo@yahoo.com.br.
} 
Iniciaremos nossa argumentação com a teoria do mínimo existencial, analisando a construção do conceito e sua caracterização como retrocesso sanitário em nosso país; a seguir, dissertaremos sobre a teoria da reserva do possível, assim como a construção do conceito e a classificação como um retrocesso na realidade jurídica brasileira e, por fim, analisaremos comparativamente os dois institutos alertando para a dissonância normativa com a Constituição da República Federativa do Brasil, em especial no que se refere à consolidação do direito à saúde.

\section{Metodologia}

A metodologia empregada no desenvolvimento deste trabalho enquadra-se no que Moreno (1) classifica como metodologia dialética. Esta metodologia reconhece que o campo do Direito Sanitário refere-se a uma realidade complexa, que demanda conhecimentos distintos e integrados e uma interação constante entre teoria e prática, para que ambas se alimentem reciprocamente, e se repensem.

Para desenvolvermos nossa argumentação realizaremos uma revisão bibliográfica sobre a temática proposta com o subsídio de artigos, livros, teses e sítios eletrônicos, utilizando a metodologia histórico-dialética que consiste em compreender uma realidade integrada no sentido de totalidade, abarcando o jurídico, o político e o econômico em sua análise.

\section{DO MÍNIMO EXISTENCIAL}

\section{A Construção do Conceito do Mínimo Existencial}

O mínimo existencial - também conhecido como "conteúdo mínimo", „mínimo vital", „núcleo essencial", „,substância mínima" dos direitos fundamentais surgiu da cultura jurídica alemã, na segunda metade do século XX. No país germânico este conceito é desenvolvido e ratificado não só no âmbito jurídico, mas, também, no legislativo e administrativo, tornando-se uma referência na solução de litígios e influenciando o direito comparado.

As teses doutrinárias sobre o mínimo existencial foram criadas na Alemanha, especificamente porque a clássica Lei Fundamental ou Constitucional de Bonn, de $1949^{2}$, não trazia em seu bojo qualquer tipo de direito social de cunho prestacional ${ }^{3}$. 
Dessa maneira, a discussão em torno da garantia de um mínimo indispensável para uma existência digna ocupou um papel preponderante tanto nas questões préconstituição (por meio de Assembleia Constituinte), quanto na constituição em si (denominada Lei Fundamental de Bonn).

Como enfatizado por Krell (2), o Tribunal Constitucional Alemão lastreou a construção do mínimo existencial em dois elementos concordantes e fundamentadores de uma interpretação hermenêutica progressista no direito atual: o princípio da dignidade da pessoa humana e o direito à vida em sua completude, ou seja, na sua integridade física e mental. Enquanto o primeiro - princípio da dignidade da pessoa humana - estava inserido de modo normativo na Lei Fundamental de Bonn, especificamente em seu artigo I, inciso I; o segundo - direito à vida em sua completa integridade - inseria-se no artigo 20, inciso I da mesma Carta Constitucional. Sendo assim, a Corte Suprema alemã determinou uma ajuda social (Sozialhilfe), com base em uma interpretação constitucional prospectiva, estipulando que o Estado, de forma obrigatória, oferecesse uma contribuição social - em forma de programa de transferência de renda - a quem comprovasse ser hipossuficiente, preenchendo, dessa forma, o vazio deixado pelo texto constitucional no que se refere aos direitos sociais, influenciando a jurisprudência e a doutrina não somente de seu país, como de outras plagas internacionais.

Portanto, segundo Krell (2), a tese do mínimo existencial foi uma espécie de mea culpa da Carta de Bonn, já que esta negligenciava qualquer tipo de direito social tendo que encontrar um instrumento jurídico capaz de restituir esse vazio de dignidade humana.

Pouco depois, logo após a Segunda Guerra Mundial, Bachof (3) conseguiu construir uma argumentação - restrita apenas à doutrina jurídica - sobre o mínimo existencial em que aliava o direito civil e político ao direito social. Sustentava que o mínimo existencial, ligado à dignidade humana, não estaria resumido apenas à questão da liberdade, mas, principalmente, a um mínimo de segurança social como saúde, educação e moradia.

\footnotetext{
${ }^{2}$ È a vigente Constituição da Alemanha.

${ }^{3}$ Excepcionalmente existe a previsão da proteção da maternidade e dos filhos, compensação de desigualdades fáticas no que diz respeito à discriminação das mulheres e dos portadores de necessidades especiais.
} 
Nessa mesma época, de acordo com Alexy (4), o Tribunal Constitucional da Alemanha começa a trilhar a argumentação supracitada de Bachof (3). Em sua jurisprudência, proferiu duas decisões fundamentais em relação aos direitos sociais prestacionais, que teve como escopo o fundamento conceitual do mínimo existencial.

Precisamente, em 1951, ocorreu a primeira decisão, que tinha como tema a assistência social. Nessa decisão, num movimento inicial de ausência de garantia, o Tribunal Constitucional Alemão desobriga o Estado de proteger o indivíduo de suas necessidades materiais e também a uma assistência totalmente gratuita.

Com a polêmica originada a partir dessa decisão, o Tribunal Alemão tenta redimirse declarando que não significa que 0 indivíduo não tenha nenhum direito constitucionalmente garantido à assistência social, o Estado pode prover uma assistência mínima, a ser formulada a posteriori. Destarte, a discussão avança e, em 1975, o Tribunal profere uma decisão em que afirma que um dos deveres inquestionáveis do Estado Alemão é a assistência aos necessitados, devendo lhes garantir "o mínimo", ou seja, condições básicas para uma existência humana digna. Dessa forma, consagrouse pela primeira vez um direito fundamental a um mínimo existencial embalado pelos ótimos desempenhos econômicos do Estado do Bem Estar Social alemão, à época.

$E$ a segunda decisão foi muito mais polêmica, tratava-se do caso de vagas nas universidades (que eram poucas) para os estudantes correspondentes ao que é o ensino médio brasileiro (que eram muitos), que pleiteavam a entrada na vida acadêmica. Portanto, foi uma questão referente ao númerus clausus. O Tribunal Constitucional Alemão proferiu uma dúbia decisão, pois ao mesmo tempo em que permitiu que todo cidadão que tivesse concluído o ensino médio deveria ingressar nas universidades (um mínimo existencial educacional), também deixou aberta a questão sobre a criação de novas vagas - questão que se resolveria com a teoria da "reserva do possível", que veremos no próximo item (5).

Depois de avaliarmos esse novo instrumento jurídico em seu país de origem, analisaremos este conceito do mínimo existencial em nosso país.

No Brasil, esse debate é muito recente, ganhando força na última década e, ainda se encontrando em permanente construção doutrinária. Juristas como Torres (5), Barcellos (6) e Sarlet (7) têm contribuído com novos enfoques sobre o tema. 
De acordo com Torres (5), as características centrais do mínimo existencial se coadunam sobremaneira com os denominados direitos da liberdade: sua condição de pré-constitucionalidade, pois é inerente à pessoa humana, independente da formação de uma Constituição; é direito público subjetivo de qualquer cidadão, fortalecendo a interpretação de que o mínimo existencial é que influencia a ordem jurídica e não o seu contrário, apresenta validade erga omnes, ou seja, tem consequências, sejam estas diretas ou indiretas, para toda a coletividade, como no exemplo de uma justificativa de estado de necessidade e, por último, apresenta-se imbuído de historicidade, vale dizer, variando de acordo com o contexto social e econômico e a identidade territorial que deseja abarcar.

Já Barcellos (6) advoga que o mínimo existencial deve preceder o princípio da dignidade da pessoal humana, devendo o Estado ofertar para os cidadãos um núcleo com um conteúdo básico, já que a efetivação do mínimo é condição sine qua non para a classificação de um ser digno ou indigno perante as características do sistema capitalista. O núcleo básico do mínimo existencial, em relação aos elementos matérias da dignidade, deve ser composto por uma proteção estrutural objetiva e subjetiva que satisfaça, minimamente, o cidadão perante o sistema capitalista em que vive, dada aí todas as características de países, sejam estes centrais ou periféricos na geopolítica estabelecida.

Barcellos (6) ainda enumera, de forma explícita, como seria constituído este mínimo existencial: saúde básica, educação fundamental, acesso à justiça e assistência aos desamparados, este último, englobando alimentação, vestuário e abrigo.

Sarlet (7) está de acordo com as construções conceituais do mínimo existencial feitas por seus colegas, porém, ele chama atenção para a restrição desse conceito, alertando que não se pode quantificá-lo de forma única e definitiva, pois o mínimo existencial varia conforme o lugar, tempo, padrão socioeconômico vigente, esfera econômica e financeira, expectativas e necessidades, que no caso da interpretação dada por esse autor, podem se confundir com desejos e aspirações individuais.

Sarlet (7) completa seu raciocínio ao elucidar como se daria a definição desse mínimo existencial, tendo como referência o papel dos legisladores e dos juízes: cabendo ao legislador a função de dispor sobre a forma da prestação, seu montante, as condições para sua fruição, entre outros aspectos a serem considerados e aos tribunais 
caberiam decidir sobre este núcleo existencial mínimo, mas apenas em casos de omissão ou desvio de finalidade por parte dos órgãos legiferantes.

A conclusão a que chegam esses juristas é que em um país com tamanha desigualdade social, ${ }^{4}$ como o Brasil, não existem elementos concretos que possam efetivar todos os direitos fundamentais para todas as pessoas, embora concordem que há uma contradição nesse tipo de argumentação, pois a erradicação da total desigualdade é um dos objetivos e fundamentos do Estado Democrático de Direito no Brasil, de acordo com a Constituição Federal.

Assim, em uma conjuntura em que nem todos os direitos fundamentais são respeitados, a teoria do mínimo existencial em nosso país permite racionalizar as supostas escassez e má gestão/má distribuição dos recursos orçamentários, sendo de fundamental importância para a atuação dos três poderes (Executivo, Legislativo e Judiciário) para garantir aos cidadãos mais necessitados um direito óbvio da cidadania, ou seja, um mínimo necessário para que possam existir de forma digna(5).

\section{O Mínimo Existencial como Retrocesso Sanitário}

Depois de analisarmos a construção do mínimo existencial, desde sua origem na Alemanha até sua chegada ao Brasil, direciona-se, a partir deste ponto, uma explanação com a incumbência de comprovar como o conceito de mínimo existencial foi construído, tendo o intuito, consciente ou não, de retroceder as conquistas abarcadas nos direitos sociais de nossa Constituição.

Para iniciar, houve uma falha teórica de nossos doutrinadores, que professam o mínimo existencial no que tange à transferência deste conceito da Alemanha para o nosso direito pátrio. Essa transferência se deu de forma mecânica, sem atentar para duas observações fundamentais: a primeira, em relação à abissal diferença de conteúdo das Cartas Políticas germânica e brasileira; a segunda, referente à distância social, formação política e econômica, também imensa, que separa a realidade desses países.

\footnotetext{
${ }^{4}$ Segundo o Programa das Nações Unidas para o Desenvolvimento (PNUD), com dados de 2010, o Brasil é o 10ํㅡㄴ país mais desigual do mundo, dentre 126 países pesquisados.
} 
Não há argumentação de defesa sobre a existência de um "mínimo existencial" no Brasil, já que nossa Constituição - classificada como dirigente, ou seja, dirige e indica ao Estado como atuar no contexto sociopolítico - erigiu um extenso rol de direitos sociais de cunho prestacional, como obrigação de executar em prol da melhoria dos serviços públicos, atingindo, dessa forma, o conjunto da população; diferentemente da Constituição Alemã, que destaca os direitos liberais, a forma de governo e o controle de constitucionalidade, quase que não citando nenhuma forma de direito social. Sendo assim, na cultura constitucional germânica, a elaboração de um mínimo de dignidade para os seus cidadãos se torna fundamental para uma sociedade que se pretenda justa e solidária, já que não há previsão constitucional sobre os direitos sociais.

Já no caso do Brasil, a construção doutrinária de um mínimo de provimentos, sejam estes materiais ou não, seria um retrocesso constitucional, pois o que seria válido e eficaz em nossa realidade seria a concretização do rol dos direitos sociais do texto constitucional, direitos esses, resultado de muita luta e organização dos movimentos sociais e não um mínimo que, ao mesmo tempo que é limitado, também limita, não somente o texto constitucional no que ele de fato poderia ser, como também a coletividade de cidadãos em seus direitos mais elementares, para a formação de uma vida digna. Dessa maneira, a tese sobre o mínimo existencial é deslocada e contraproducente em nosso país, retrocedendo conquistas constitucionais.

E complementando, a Alemanha, assim como os países centrais da Europa (França, Inglaterra, Itália), goza de uma tradição de um Estado Social ainda atuante, apesar de todos as restrições sofridas ${ }^{5}$, podendo o país germânico se dar ao luxo de não constitucionalizar direitos sociais. Já o Brasil, país de imensa desigualdade social, não pode confiar sua esperança de ratificação dos direitos sociais a uma espécie de mínimo vital, devendo perseguir, intermitentemente, os direitos fundamentais sociais de nossa Constituição em sua completude. Como relata Krell (2) não se trata de analisar a Constituição como um texto bíblico, beirando o messianismo, mas apenas exigir que o Estado brasileiro - e Estado no sentido mais lato possível: Executivo, Legislativo, Judiciário, Conselhos Populares - leve a sério os mandamentos constitucionais.

\footnotetext{
${ }^{5}$ Principalmente no contexto da crise econômica atual, que teve início em 2007/2008.
} 
Perquirindo incisivamente sobre a tentativa de construção do conceito do mínimo existencial, vimos que, até o momento, há uma hesitação sobre a cientificidade desse conceito, sobre o que, realmente, ele abrange. Como ressalta Wang (8) a teoria do mínimo existencial tem a pretensão de definir o núcleo essencial dos direitos sociais, como uma espécie de guia e farol para o intérprete na busca da concretização desses direitos, mas o mínimo em análise demonstra-se variável, influencia e é influenciado por uma série de circunstâncias e especificidades de cada caso concreto, colocando em dúvida, portanto, a capacidade de servir de referência para a definição do tal mínimo de dignidade. Algumas perguntas são importantes para tentar resolver o problema colocado: como é formado um núcleo essencial de um direito, qual sua abrangência, como se inicia e como se finda? Não há receita de bolo para definir os contornos do mínimo existencial, muito menos servir de referência.

Netto (9) também reforça essa análise ao questionar a falta de parâmetros para definir o conceito de mínimo existencial e também contesta a ausência sobre quem deve delimitar e dar eficácia ao conceito, destacando que não há contornos definidos para a tomada de decisão e ação no plano concreto, seja numa lei, na administração ou em uma decisão judicial, a complementação desse estágio via controle social também é deficitária, não há ainda uma sistematização concreta sobre como e em quais situações esse mínimo definiria o núcleo de direitos sociais e, o mais importante, quem o definiria.

Netto (9) e Wang (8) também atentam para o fato de haver uma contradição sobre a decisão de um mínimo existencial, caso haja conflito institucional entre algum dos três Poderes de nossa República, podendo propiciar uma rusga ou até mesmo crise que se reflita sobre as políticas públicas.

Sobre a especificidade do "direito à saúde", o mínimo existencial está sendo desenvolvido com o claro intuito de restringi-lo somente à saúde básica, como vimos na definição de Barcellos (6). Também serve para legitimar projetos de lei que almejam restringir ou excluir o direito à saúde da Constituição, principalmente de seu art. 196 , que sustenta a universalidade e integralidade do direito à saúde, demonstrando, dessa forma, um explícito retrocesso social.

O fenômeno da judicialização da saúde - que vem a ser a luta constante dos cidadãos pelo efetivo cumprimento da Constituição - vem sofrendo críticas com um sério ranço conservador, legitimadas pelo mínimo existencial. Com exceção de casos como 
medicamentos ou tratamentos sem eficácia comprovada ou que possuem alternativas ao paciente comprovadamente com o mesmo resultado científico e com custo menor ao erário, o juiz não poderá justificar sua negativa de atendimento ao paciente que recorra à justiça com base no argumento do mínimo existencial, pois em praticamente todas essas situações está se relacionando com o delicado tema do direito inalienável à vida e à dignidade da pessoa humana, que não corresponde nem de longe a um certo „mínimo vital", pois para a manutenção da vida deve-se atentar para o máximo de atendimento e tratamento, ocasionando a busca pelo melhor dos medicamentos, sendo este um dos exemplos mais recorrentes da denominada judicialização da saúde.

Amaral (10) e Netto (9) ratificam essa análise ao defender que o Estado-Juiz não deve considerar nem mesmo se o requerente tem recursos financeiros para custear 0 tratamento/medicamento requerido, já que em poucos casos se justificaria uma não concessão, pois a maior parte dos gastos com medicamentos concedidos pelo Poder Judiciário vai para aquisição de produtos de altíssimo custo, ou seja, não há fornecimento nem mesmo pelo plano privado de saúde, mesmo com uma série de isenções e desonerações que o Governo presenteia esses grupos empresários do ramo sanitário ${ }^{7}$. Deve-se pensar, para amenizar o quadro da judicialização da saúde, também o papel da saúde privada em nosso sistema de saúde, inclusive em nosso sistema público (SUS), que tem, como desafio, que continuar a ser único (11).

Vimos, portanto, que o denominado mínimo existencial tem como escopo retroceder os direitos sociais à categoria de um direito natural, um mínimo de cidadania que não condiz com a natureza preceptiva de nossa Constituição.

Assim, pela orientação hermenêutica progressista de nossas normas constitucionais, interpretamos com base no princípio da proibição do retrocesso social ${ }^{8}$, buscando a anulação do conceito de mínimo existencial com o argumento de que não podemos voltar a um estágio antiquado em que só havia a consolidação formal de direitos que representavam „migalhas de cidadania" (12).

\footnotetext{
6 “Art. 196. A saúde é direito de todos e dever do Estado, garantido mediante políticas sociais e econômicas que visem à redução do risco de doença e de outros agravos e ao acesso universal e igualitário às ações e serviços para sua promoção, proteção e recuperação." CF/88.

${ }^{7}$ Ocké-Reis (2013) estima que a renúncia de arrecadação fiscal em saúde, no ano de 2011, alcançou significativos $R \$ 16$ bilhões, o equivalente a $22,5 \%$ do investimento público federal na área.
} 
Para além do positivismo jurídico, ousa-se também analisar o conceito de mínimo existencial comparando e fazendo o contraponto com o conceito de básico social, ou seja, em uma análise para além do direito. Pereira ${ }^{13}$ destaca que não se pode confundir os termos mínimo e básico, pois, apesar de sua quase irmandade semântica, são bastante diferentes em termos político-sociais. Enquanto o mínimo exige uma proteção por baixo, rasteira, somente se atentando às necessidades biológicas para a pura e simples sobrevivência, sem se preocupar com o desenvolvimento físico e mental do ser humano, para que alcance percepção crítica sobre seu lugar e posicionamento perante o sistema capitalista; o básico deve ser algo fundamental, para além de uma satisfação simplista, que dê oportunidades de fato para que o ser humano se reconheça como tal, no completo bem-estar de sua saúde física, concomitante com um grau subjetivo de autonomia cidadã, refletindo sobre seus objetivos e crenças.

Pereira (13), ao nos apresentar a construção intelectual do mínimo, só ratifica a perspectiva de retrocesso incluída nesse conceito. A autora inicia trazendo as contribuições do representante da Escola Austríaca de Economia, Friedrich Hayek, em defesa de um mínimo de renda somente para pessoas que não apresentem condições para participação no mercado de trabalho: enfermas, pessoas física e mentalmente incapazes, viúvas e órfãos. Hayek (14) defende um mínimo como dever moral e não cívico, uma mínima rede de segurança para amenizar a pobreza extrema, numa conceituação de dimensão biológica ou mero alívio para necessidades animais.

A defesa de um mínimo para Hayek (14) é expansiva, englobando uma série de ações no campo da micro e macroeconomia: a defesa de um Estado Mínimo, políticas assistencialistas mínimas e focalizadas, atuação do mercado em políticas públicas estratégicas, preferindo até mesmo uma ditadura liberal frente a uma democracia que não cumpra com os ideários de sua doutrina.

\footnotetext{
${ }^{8}$ O Princípio da Proibição do Retrocesso Social defende a garantia dos direitos sociais constitucionalizados, protegendo-os de qualquer iniciativa de restrição e/ou supressão dos mesmos.
} 
O segundo autor apresentado por Pereira (13) é o filósofo político John Rawls, que apresenta a defesa de um mínimo efetivado pelo Estado para os mais pobres (de acordo com um corte de renda estabelecido) para equacionar os desequilíbrios propiciados pelo mercado. Defende uma ordem léxica em que se pressupõe que o princípio da liberdade e oportunidade esteja à frente do princípio da igualdade, demonstrando pífia preocupação com uma igualdade material, fortalecendo, dessa forma, a igualdade formal, em que a lex mercatoria estaria acima de qualquer princípio distributivo.

Pereira (13) ainda destaca quatro semelhanças entre Hayek (14) e Rawls (15): a) o mercado tem papel de destaque numa sociedade onde as diferenças das classes sociais são resolvidas com base em uma folha de papel, qual seja o contrato, sendo uma das facetas mais versáteis e convincentes da legitimação do sistema capitalista; b) apologia do fetichismo da mercadoria, que é o modo pelo qual as formas econômicas do capitalismo ocultam as relações sociais a elas subjacentes, como, por exemplo, quando o capital, como quer que seja compreendido, e não a mais-valia, é tido como a fonte do lucro; c) incentivo às desigualdades criadoras como basilares para a manutenção de uma competição no sistema capitalista, naturalizando a pobreza numa espécie de darwinismo social, em que os direitos sociais são vistos como empecilho ao avanço econômico e; d) inclusão individual, pois o mínimo existencial deve favorecer apenas a indivíduos, por isso o destaque para a dignidade da pessoa humana, não devendo referir-se à coletividade ou classes sociais.

Portanto, o conceito de mínimo seria próximo de um mínimo de subsistência, resposta isolada e emergencial aos efeitos da pobreza extrema, uma política assistencialista conjuntural, que legitima as desigualdades sociais e a concentração de renda numa sociedade dividida em classes.

Para contrapor ao mínimo surge o conceito de básico social, demonstrado por Pereira (13), com base na tese de Doyal e Gough (16), que conceitua o básico como uma política em movimento rumo ao alargamento social de direitos, numa integralidade e junção com as três gerações do direito: liberal, social e difuso, e não somente com políticas assistencialistas e focalizadas. 
Os programas, na conceituação do básico social, devem estar encadeados, complementando-se, mutuamente, no caso da saúde pública brasileira, por exemplo, o Programa Saúde da Família (PSF) deve ser efetivado juntamente com a vigilância sanitária, saneamento básico, assistência, prevenção, entre outros.

Para Pereira (13), com base nos autores supracitados, o básico social deve conter duas características imprescindíveis: ser objetivo e universal. Ser objetivo no sentido de que sua especificação teórica e empírica deve ser independente de preferências ou desejos pessoais; e universal, no que se refere às consequências do não cumprimento de um bem estar à coletividade, proporcionando sérios prejuízos decorrentes de sua não satisfação adequada, em qualquer pessoa, em qualquer parte do mundo, em qualquer cultura. A definição de sérios prejuízos também é conceituada por Pereira (13), que menciona como impactos negativos relevantes que possam impedir ou por em sério risco a possibilidade objetiva e subjetiva dos seres humanos de viver física e socialmente em condições de poder expressar a sua capacidade de participação ativa e crítica.

Doyal e Gough (16) destacam que as necessidades humanas básicas objetivas e universais são a „saúde física" e a „autonomia", que devem ser efetivadas por meio de uma política pública atuante, de modo conjunto. Ambas são pressupostos iniciais para uma vida digna, não se resumindo como um fim em si mesmas. A saúde física seria como um axioma para o desfrute da vida, sendo uma necessidade humana primária, que tem como indicadores básicos a taxa de mortalidade e a expectativa de vida. A saúde física é como um lastro para o alcance da autonomia, esta seria a capacidade do indivíduo de eleger objetivos e crenças, de valorá-los com discernimento e de pô-los em prática sem opressões, não somente no sentido de se fazer ciente de sua posição como indivíduo, mas, principalmente, como pertencente a uma coletividade, respeitando regras e valores que devem ser construídos de forma democrática e participativa.

Portanto, o básico social se diferencia do mínimo existencial no sentido de que é uma política estrutural, exigindo reformas de base, como a efetivação de uma reforma sanitária com base em nossa Constituição, política de Estado e não de Governo, com total afinidade com os ditames constitucionais. No caso do direito sanitário, isso significa a luta pela concretização dos princípios do Sistema Único de Saúde (SUS), quais sejam a universalidade, integralidade, equidade, de acordo com a implementação de políticas sociais e econômicas, com o fim de ratificar objetiva e subjetivamente a saúde 
Cad. Ibero-Amer. Dir. Sanit., Brasília, v.4, n.3, jul./set. 2015 ISSN 2358-1824

pública brasileira.

Depois de analisarmos criticamente o conceito de mínimo existencial, passaremos, a seguir, à análise de outro retrocesso sanitário: a reserva do possível.

\section{DA RESERVA DO POSSÍVEL}

\section{A Construção do Conceito da Reserva do Possível}

A teoria da reserva do possível também deve a sua origem à Alemanha, especificamente à Corte Constitucional Federal germânica, na década de 1970, para ser um contraponto, um limite, às „benesses" do Estado do Bem Estar Social. Tudo começou com um julgado do Tribunal Constitucional alemão referente ao acesso, pelos estudantes, às vagas das universidades públicas - numerus-clausus Entscheidung ${ }^{9}$, em 18 de julho de 1972 , baseado no artigo 12, § 1ำ da Constituição ${ }^{10}(17)$.

A Corte apreciou um caso no qual uma ação judicial tinha como escopo permitir a determinado estudante cursar o ensino superior público, no caso específico, a Faculdade de Medicina. Tal ação se baseava na garantia prevista pela Lei Federal alemã (Lei Fundamental de Bonn) que garantia a livre escolha de trabalho, ofício ou profissão, tendo em vista que não havia disponibilidade de vagas em número suficiente para todos os interessados em frequentar as universidades públicas.

$\mathrm{Na}$ decisão proferida pelo Tribunal, ficou estabelecido que só se pode exigir do Estado o atendimento de um determinado interesse, ou a execução de uma prestação específica em benefício do interessado, desde que observados os limites da razoabilidade e proporcionalidade; e a decisão completava o julgado relatando que os sujeitos à reserva do possível devem sopesar a racionalidade de cada caso concreto, refletindo sobre o aspecto econômico do Estado (2).

Ou seja, essa conclusão obstaculizaria qualquer pretensão acima de um patamar considerado logicamente razoável de exigências sociais, razão pela qual o Tribunal decidiu, neste caso específico, que o Poder Público não estaria obrigado a disponibilizar um número ilimitado de vagas para acolher todos os interessados em ingressar nas uni-

\footnotetext{
${ }^{9} \overline{\mathrm{O} \text { mesmo caso do mínimo existencial. }}$.

10 "Todos os alemães têm o direito de eleger livremente a sua profissão, o lugar de trabalho e o lugar de formação" tradução de "alle deutschen haben das recht, beruf, asbeitsplatz und ausbildungsstätte frei zu wählen" (DEUTSCHLAND, 2012).
} 
versidades públicas. Esse caso teve grande repercussão social e acabou incidindo sobre casos semelhantes.

A teoria da reserva do possível foi se desenvolvendo na Europa até seu advento no âmbito jurídico brasileiro, evoluindo de uma maneira mais sistematizada a partir dos anos 2000, juntamente com o "mínimo existencial".

No Brasil, os mesmos doutrinadores ${ }^{11}$ que se debruçaram sobre o instituto do mínimo existencial também se prontificaram a estudar com mais afinco a reserva do possível. Barcellos (6) relata que o advento da reserva do possível é concernente ao debate sobre a limitação dos recursos disponíveis frente às numerosas necessidades da população, principalmente em relação às requisições de atendimento à saúde, especificamente em relação aos altos custos dos medicamentos. A autora atenta para o fato de que há um limite orçamentário e que, consequentemente, pode terminar em uma frustração para a população ao constatar que o Estado não tem recursos suficientes para suas infinitas necessidades.

Autores como Sarlet (18), Kelbert (17) e Moreira (19) definem a reserva do possível em três características principais: a) disponibilidade fática de recursos; b) disponibilidade jurídica de recursos materiais e humanos e; c) a proporcionalidade na prestação.

Sobre a disponibilidade fática de recursos, a reserva do possível é interpretada para legitimar a ausência total de recursos para a realização de direitos prestacionais, a observação a ser registrada é que essa ausência de recursos deve ser comprovada, não apenas alegada, sob pena de responsabilidade do administrador. Destaca-se que a ausência de recursos não se restringe somente aos recursos financeiros, mas também aos recursos humanos ou materiais, como por exemplo, a falta de médicos e de leitos em hospitais.

Sobre a segunda característica da reserva do possível - disponibilidade jurídica de recursos materiais e humanos - os autores supracitados afirmam que há recursos existentes, porém não estão disponíveis e não podem ser utilizados, é o caso, portanto, da problemática ligada à autonomia jurídica de disposição, já que o Estado deve ter a

\footnotetext{
${ }^{11}$ Barcellos (6), Sarlet (18), entre outros.
} 
capacidade jurídica (poder de dispor), sem o qual nada lhe adiantam os recursos existentes, assim, a peça orçamentária não possui caráter vinculante para o administrador, com exceção do remanejamento de verbas - que deve ser plenamente justificado - previsto na própria lei orçamentária.

Sobre a terceira e última característica da reserva do possível - proporcionalidade na prestação - está sendo construída no sentido de analisar cada caso concreto com todas as suas nuances de cunho político, jurídico e econômico, já que o instituto da reserva do possível apresenta uma forma dialética em relação à prestação de direitos fundamentais sociais: pode ser apresentada como um limite fático e jurídico, como vimos acima; mas, ao mesmo tempo, apresenta-se como uma garantia de efetivação dos direitos relatados, caso seja considerado o núcleo essencial mínimo desses direitos, o que, em ambos os casos, pode transparecer a ideia de retrocesso, já que os limites gerados, seja numa interpretação lata sobre o tema, seja demonstrando critérios como proporcionalidade, sempre trabalharão com o foco de restringir ou limitar a efetivação de direitos sociais, como o direito à saúde.

No Brasil, nossos doutrinadores supramencionados foram mais duros e restritivos do que os seus colegas alemães, pois essa tripartição se diferencia do conceito original germânico em relação à segunda característica descrita - "disponibilidade jurídica de recursos materiais e humanos" - que significa que, antes de serem garantidos os direitos sociais, deve-se observar a disposição orçamentária específica, priorizando o orçamento aos direitos.

Portanto, só se podem efetivar direitos na medida do possível, pois o Estado, supostamente, não tem recursos para além dessa escassa possibilidade financeira. Ao limitar a amplitude de direitos sociais aos cidadãos, se incorre, fatalmente, em uma restrição desses direitos, havendo, portanto, um claro retrocesso.

\section{A Reserva do Possível como Retrocesso Sanitário}

Assim como o mínimo existencial, o conceito de reserva do possível não pode ser aplicado em nossa realidade, como destaca Krell (2). Caso os doutrinadores ou operadores do Direito alemão se confrontassem com o quadro socioeconômico de exclusão social do Brasil e, consequentemente, com a ausência de condições mínimas para o usufruto de uma existência digna, passariam a exigir a atuação do Poder 
Judiciário para, juntamente com outros poderes da República, tentar amenizar as desigualdades sociais existentes.

Krell (2) ainda destaca que se as condições para a efetivação dos direitos econômicos, sociais e culturais se resumirem a existência de recursos financeiros nos caixas de governos, a eficácia em torno dessa efetivação se aproximará de zero, realçando que não se devem colocar os direitos sociais abaixo das condicionantes econômicas, sob o risco de relativizar a universalidade desses direitos, podendo ocasionar uma crise do incipiente Estado Social e Democrático de Direito brasileiro, que ainda está em via de consolidação, não sendo positivo comparar com uma economia central do continente europeu, com outro tipo de formação cultural e institucional.

Cunha Jr. (20), ratificando o pensamento de Krell (2), é ainda mais incisivo, ao constatar que, mesmo com os avanços conjunturais nos últimos anos, representados por políticas de transferência de renda, não há mudança estrutural efetivada no Brasil, o qual ainda figura entre os países líderes de estatísticas de concentração de renda e de população sobrevivendo abaixo da linha de pobreza. Tal conjuntura sinaliza que devemos exigir que os direitos sociais sejam retirados da condição de reféns, do condicionamento provocado propositadamente pela justificativa da reserva do possível.

Continuando nossa análise sobre a reserva do possível, este conceito, como relatamos, é dividido em dois tipos: reserva do possível fática e jurídica. O primeiro se caracteriza a um contingenciamento financeiro, a que se encontram submetidos os direitos prestacionais; e, o segundo, diz respeito à ausência de previsão orçamentária que destine os recursos à consecução de um determinado interesse, ou requerimento de uma determinada demanda (21).

Sobre a reserva do possível fática há também crítica sobre a ausência de critérios que possam balizá-la, correndo o risco de se tornar uma ficção conceitual, como relata Souza (22):

A reserva do possível fática (ausência de recursos) é um conceito ainda mais problemático, ainda mais fluido, ainda mais polêmico que o de mínimo existencial. Tem sido alegada indiscriminadamente pelo Poder Público para se furtar à implementação de direitos fundamentais e não existem ainda critérios objetivos para delimitá-la. 
Farena (23) destaca o risco de se colocar como pressuposto básico para a efetivação dos direitos sociais a quantidade de recursos suficientes do Estado, podendo representar um retrocesso social que imobilize as pretensões contidas em nossa Carta Magna:

As alegações de negativa de efetivação de um direito social com base no argumento da reserva do possível devem ser sempre analisadas com desconfiança. Não basta simplesmente alegar que não há possibilidades financeiras de se cumprir a ordem judicial; é preciso demonstrá-la. O que não se pode é deixar que a evocação da reserva do possível converta-se em verdadeira razão de Estado econômico, num Al-5 econômico que opera, na verdade, como uma anti-Constituição, contra tudo o que a Carta consagra em matéria de direitos sociais.

Já sobre a reserva do possível jurídica, a crítica é sustentada pela defesa de um maior protagonismo do Poder Judiciário no que tange ao controle da legislação orçamentária. Para Grau (24), a atuação do Poder Judiciário, em colaboração com os demais Poderes, deve ser totalmente pró-desenvolvimento dos direitos sociais, combatendo todo o retrocesso que venha a surgir, pois o processo de aplicação do direito, por meio do mandamento advindo das decisões judiciais é um processo de permanente recriação e atualização do direito, abrindo espaços para inovações e retirando principalmente o juiz do estado de letargia de ser apenas „a boca da lei", devendo não apenas reproduzir, mas produzir o direito com o intuito de efetivar a aplicação constitucionalmente imediata de um direito fundamental social, é o caso de inverter as prioridades. O direito social é que deve influenciar o orçamento e não o contrário.

Para concluirmos sobre a reserva do possível fática e jurídica, destacaremos a passagem de Cunha Jr. (20), na qual ele defende que existem recursos financeiros no âmbito do Estado para garantir os direitos sociais, e o que ocorre na realidade é uma má distribuição desses recursos e, até mesmo, desvios ilícitos. Nesse caso, sustenta o autor, de forma implícita, é que o Poder Judiciário deve atuar tendo como referência o princípio da proibição do retrocesso social, para evitar teses restritivas como a reserva do possível, ao alertar sobre instrumentos de fiscalização sobre o gasto público, para evitar casos como desvios de verbas com obras superfaturadas, cartões corporativos, corrupção ativa e passiva, empresas corruptoras e corruptas, cultura „do favor e do jeitinho", para que esse dinheiro seja aplicado para as necessidades básicas do 
do ser humano, de acordo com o princípio da dignidade da pessoa humana.

É axiomático que o direito à saúde, assim como todos os direitos, não é absoluto, devendo-se analisar a proporcionalidade, a razoabilidade e o caso específico em si. Mas, usar o argumento de que não há recursos disponíveis, de modo irresponsável, ou seja, sem comprovação empírica, é característica de setores que tem como escopo principal restringir e, até mesmo, retirar o direito à saúde da Constituição, atacando, principalmente, os princípios da integralidade e da universalidade. É urgente, também aqui, que a hermenêutica jurídica atue com o fito de proibir este retrocesso social denominado "reserva do possível".

Complementaremos esse raciocínio com a citação de trecho da tese de doutorado de Fernando Aith (25), intitulada „Teoria Geral do Direito Sanitário Brasileiro":

[...] a diretriz de integralidade das ações e serviços públicos de saúde representa um importante instrumento de defesa do cidadão contra eventuais omissões do Estado, pois este é obrigado a oferecer, prioritariamente, o acesso às atividades preventivas de proteção da saúde. A prevenção é fundamental para evitar a doença, entretanto, sempre que esta acometer um cidadão, compete ao Estado oferecer $o$ atendimento integral, ou seja, todos os cuidados de saúde cabíveis para cada tipo de doença, dentro do estágio de avanço do conhecimento científico existente. Assim, sempre que houver uma pessoa doente, caberá ao Estado fornecer o tratamento terapêutico para a recuperação da saúde dessa pessoa de acordo com as possibilidades oferecidas pelo desenvolvimento científico. Assim, não importa o nível de complexidade exigido, a diretriz de atendimento integral obriga o Estado a fornecer todos os recursos que estiverem ao seu alcance para a recuperação da saúde de uma pessoa, desde o atendimento ambulatorial até os transplantes mais complexos. Todos os procedimentos terapêuticos reconhecidos pela ciência e autorizados pelas autoridades sanitárias competentes devem ser disponibilizados para a proteção da saúde da população.

Portanto, a consecução do direito à saúde por parte do Estado é obrigatória e deve atender a todos. A reserva do possível não deve ser usada como argumento a obstaculizar essa conquista da nossa cidadania, pois, como vimos, ela necessita de uma melhor definição em relação a seus critérios objetivos, assim como precisa comprovar seu pressuposto básico - a escassez de recursos por parte do Estado brasileiro. 


\section{A Relação entre o Mínimo Existencial e a Reserva do Possível}

Tanto o mínimo existencial quanto a reserva do possível, em termos históricojurídicos, são institutos incipientes que ainda não encontraram tratamento exaustivo por parte da doutrina. Dessa maneira, deve-se estudar o tema com atenção, pois há uma relação direta entre estes institutos e a efetivação dos direitos fundamentais, incluindo aqui o direito à saúde.

Para demonstrarmos da melhor forma possível a relação entre ambos os institutos em tela e as indagações contidas neles, recorremos a Oliveira e Calil (26) que questionam, primeiramente, sobre a precedência de um instituto sobre o outro, já que não há uma comprovação de qual deles dá a devida sustentação à existência doutrinária do outro. A pergunta a que os autores não encontram resposta é a seguinte: se a reserva do possível limita os direitos sociais a um mínimo necessário a uma existência digna, ou a reserva do possível, inclusive reserva financeira, seria de aplicação geral, apenas encontrando restrição em relação a um núcleo dignitário mínimo?

Logo depois, complementando o raciocínio, Oliveira e Calil (26) levantam várias questões sobre a relação entre o mínimo existencial e a reserva do possível, como, por exemplo, em torno da indeterminação se a reserva do possível é empecilho e entrave à aplicação fática dos direitos prestacionais, com exceção ao núcleo essencial que completa esses direitos ou se a reserva do possível é a responsável por delinear o mínimo essencial, restringindo, dessa forma, todos os direitos que a ele não pertencem:

Caso se entenda que a reserva do possível é um obstáculo fático aos direitos prestacionais, está-se perante uma teoria absoluta do núcleo essencial, pois seriam intangíveis pela reserva do possível, nada mais podendo olvidar a exigibilidade desse conjunto de direitos subjetivos.

Ao contrário, se a conclusão for de que o delineamento do mínimo essencial é dado pela reserva do possível, esse conjunto de direitos derivará de uma ponderação, sendo que pode ser restringido no caso concreto. Sob este prisma, o mínimo essencial apenas existiria em decorrência da existência da reserva do possível, o que não ocorre em verdade. Adotada esta tese, a reserva do possível deixa de ser um elemento da ponderação, passando a fazer parte do embate, considerando-a, sim, como característica dos direitos prestacionais (26).

Portanto, como se vê, ainda há muito que destrinchar sobre a relação entre o mínimo existencial e a reserva do possível e, como já referido, temos que continuar atentos às elaborações sobre esses dois institutos, poise les apresentam uma relação 
direta e constante com a legitimação e justificativa para a restrição e/ou exclusão dos direitos fundamentais sociais, em especial, o direito à saúde.

\section{Considerações Finais}

A construção conceitual das teorias do mínimo existencial e da reserva do possível deve ser avaliada com razoabilidade e proporcionalidade ao ser aplicada no Brasil, pelo fato de sermos um país de modernidade tardia e, consequentemente, termos uma situação juspolítica e econômico-social muito distinta da Alemanha; além, das situações históricas inerentes a cada contexto à época de aplicação dessas teses.

A análise comparativa dos documentos constitucionais de ambos os países não deixam dúvidas quanto à dissonância hermenêutica da aplicação desses conceitos: enquanto na Alemanha a origem e desenvolvimento do mínimo existencial e da reserva do possível podem ser considerados como instrumentos de salvaguarda da dignidade da pessoa humana, no Brasil constata-se um retrocesso social, principalmente em relação ao direito constitucional à saúde.

Nosso direito à saúde, estruturado e consolidado pela Constituição de 1988, apresenta como características principais sua universalidade, integralidade e participação social subsumidos em um Sistema Único de Saúde (SUS), que ratifica esse direito social fundamental de relevância pública.

A aplicação do mínimo existencial e da reserva do possível limitaria as conquistas do SUS a um mínimo sanitário represado por restrições orçamentárias, não efetivando o direito à saúde em todos os seus níveis, nem reconhecendo seus objetivos, fundamentos e princípios, obstaculizando as conquistas e anulando a tentativa de ratificação do direito sanitário constitucional brasileiro.

Dessa forma, é necessário pensarmos alternativas doutrinárias e conceituais coerentes com a efetivação do direito à saúde no Brasil, para não endossarmos projetos de retrocessos sanitários com o intuito de restringir e, até mesmo, extinguir o SUS de nossa Constituição. 


\section{Referências Bibliográficas}

1 Moreno N. Lógica Marxista e Ciências Modernas. São Paulo: Sundermann; 2007.

2 Krell AJ. Direitos Sociais e Controle Judicial no Brasil e na Alemanha: Os (Des) Caminhos de um Direito Constitucional "Comparado". Porto Alegre: Sergio Antonio Fabris; 2002.

3 Bachof O. Begriff und Wesen des Sozialen Rechtsstaates. VVDStRL. 1954 [Acesso em 30 abr 2015], n. 12. Disponível em: http://www.degruyter.com/view/product/667..

4 Alexy R. Teoria dos Direitos Fundamentais. São Paulo: Saraiva; 2011.

5 Torres RL. O Direito ao Mínimo Existencial. Rio de Janeiro: Renovar; 2009.

6 Barcellos AP. A Eficácia Jurídica dos Princípios Constitucionais: O Princípio da Dignidade da Pessoa Humana. Rio de Janeiro: Renovar; 2012.

7 Sarlet IW. A Eficácia dos Direitos Fundamentais. Porto Alegre: Livraria do Advogado; 2012.

8 Wang DWL. Reserva do Possível, Mínimo Existencial e Direito à Saúde: Algumas Aproximações (Resenha). Revista de Direito Sanitário [Internet]. 2009 [Acesso 10 mar 2015], 10(1): 308-318. Disponível em http://www.revistas.usp.br/rdisan/article/view/13158/14965.

9 Netto LC. O Princípio de Proibição de Retrocesso Social. Porto Alegre: Livraria do Advogado; 2010.

10 Amaral G. Direito, Escassez e Escolha. Rio de Janeiro: Lumen Juris; 2010. 11

Ocké-Reis CO. SUS: O Desafio de Ser Único. Rio de Janeiro: Fiocruz; 2012. 12

Marmelstein, G. Curso de Direitos Fundamentais. São Paulo: Atlas; 2011.

13 Pereira P. Necessidades Humanas. São Paulo: Cortez; 2011.

14 Hayek F. O Caminho da Servidão. São Paulo: Instituto Ludwing von Mises. Brasil; 2010.

15 Rawls J. Uma Teoria da Justiça. São Paulo: Martins Fontes; 2000.

16 Doyal L, Gough I. Teoria de las Necesidades Humanas. Madrid: Icaria;2010.

17 Kelbert F. Reserva do Possível e a Efetividade dos Direitos Sociais no Direito Brasileiro. Porto Alegre: Livraria do Advogado; 2011. 
18 Sarlet IW, Figueiredo MF. Reserva do Possível, Mínimo Existencial e Direito à Saúde: Algumas aproximações. In: SARLET, I. W.; TIMM, L. B. Direitos Fundamentais: Orçamento e Reserva do Possível. Porto Alegre: Livraria do Advogado; 2008. p. 13-50.

19 Moreira A. As Restrições em Torno da Reserva do Possível: uma análise crítica. Belo Horizonte: Fórum; 2011.

20 Cunha JRD da. Controle de Constitucionalidade: Teoria e Prática. Porto Alegre: Jus Podivm; 2014.

21 Pereira ALP. Reserva do Possível: Judicialização de Políticas Públicas e Jurisdição Constitucional. Curitiba: Juruá; 2014.

22 Souza LM. Reserva do Possível x Mínimo Existencial: O Controle de Constitucionalidade em Matéria Financeira e Orçamentária como Instrumento de Realização dos Direitos Fundamentais. In: XVI Congresso Nacional do CONPEDI, 2008. Brasília. [Acesso em 30 abr 2015]. Disponível em:

http://www.conpedi.org.br/manaus/arquivos/anais/bh/luciane moessa de souza2.pdf.

23 Farena DA. Saúde na Constituição Federal. [Internet]. Boletim do Instituto Brasileiro de Advocacia Pública (jan. 1997); São Paulo, 3 (4):12-14.

24 Grau E. A Ordem Econômica na Constituição de 1988. São Paulo: Malheiros; 2011.

25 Aith F. Teoria Geral do Direito Sanitário Brasileiro. [Tese]. São Paulo: Programa de Doutorado em Serviços de Saúde Pública - Faculdade de Saúde Pública, Universidade de São Paulo, São Paulo; 2006. [Acesso em 30 abr 2015]. Disponível em: http://www.teses.usp.br/teses/disponiveis/6/6135/tde-23102006-144712/.

26 Oliveira RSL, Calil MLG. Reserva do Possível, Natureza Jurídica e Mínimo Existencial: Paradigmas para uma definição. In XVI Congresso Nacional do CONPEDI, 2008. Brasília. [Acesso em 30 abr 2015]. Disponível em: http://www.conpedi.org.br/manaus/arquivos/anais/brasilia/11 369.pdf 